\title{
PERCURSO UNIVERSITÁRIO DE ALUNAS/OS COM DEFICIÊNCIA EM INSTITUIÇÃO DE ENSINO PRIVADA
}

\author{
UNIVERSITY'S PATH OF STUDENTS WITH DISABILITIES IN A PRIVATE \\ EDUCATIONAL INSTITUTION
}

\author{
Denise Macedo Ziliotto \\ Pós Doutora em Educação \\ Universidade La Salle \\ Canoas, RS - Brasil \\ denise.ziliotto@unilasalle.edu.br \\ Amanda Burchert \\ Mestre em Educação \\ Universidade La Salle \\ Canoas, RS - Brasil \\ amandaburchert@gmail.com
}

\author{
Henrique Carvalho \\ Graduado em Gestão de Recursos Humanos \\ Universidade La Salle \\ Canoas, RS - Brasil \\ hfc-93@hotmail.com
}

Resumo: O ingresso de estudantes com deficiência em cursos de graduação é resultado de fatores como a expansão da educação superior e as políticas públicas de acesso, ensejando discussões acerca da efetividade na óptica inclusiva. Buscando avaliar a experiência destas/es acadêmicas/os, a investigação teve como objetivo analisar o percurso de alunos com deficiência, a partir da perspectiva de histórias de vida. Em termos metodológicos, trata-se de uma pesquisa qualitativa, tendo entrevistas como instrumento de coleta de dados, realizadas com oito alunas/os formandas/os em instituição de ensino superior privada. Os resultados abordam questões como aprendizagem, relação com professoras/es e colegas, diferenças entre contexto universitário / escolar e percurso universitário. Evidencia-se a consecução inicial da acessibilidade arquitetônica e a subsequente construção de condições pedagógicas e relacionais para as/os estudantes com deficiência revelando, portanto, novos desafios a serem enfrentados por toda a comunidade acadêmica.

Palavras-chave: acadêmicos; pessoas com deficiência; inclusão; universidade.

Abstract: The entry of students with disabilities in undergraduate courses is an effect of factors such as the expansion of higher education and access policies, giving rise to discussions about effectiveness from an inclusive perspective. Seeking to evaluate the academic experience, the investigation aimed to analyze the path of students with disabilities, from the perspective of life stories. In methodological terms, this is a qualitative research, using interviews as data collection instrument, carried out with eight students, who are about to graduate, in a private higher education institution. The results address issues such as learning, relationship with teachers and colleagues, differences between university / school context and university path. It evidences the initial achievement of architectural accessibility and the subsequent construction of pedagogical and relational conditions for students with disabilities, thus revealing new challenges to be faced by the entire academic community.

Keywords: academics; disabled people; inclusion; university.

Para citar - (ABNT NBR 6023:2018)

ZILIOTTO, Denise Macedo; BURCHERT, Amanda; CARVALHO, Henrique. Percurso universitário de alunas/os com deficiência em instituição de ensino privada. Eccos - Revista Científica, São Paulo, n. 57, p. 1-14, e8947, abr./jun. 2021. Disponível em: https://doi.org/10.5585/eccos.n57.8947. 


\section{Introdução}

Considerando a educação como um direito de todos, as instituições de ensino superior no Brasil devem proporcionar condições de acesso e utilização de seus ambientes para pessoas com deficiência ou com mobilidade reduzida nas salas de aula, bibliotecas, auditórios, ginásios, instalações desportivas, laboratórios, áreas de lazer e sanitários. Há a obrigatoriedade do ensino de LIBRAS em todos os cursos de formação de professoras/es e de fonoaudiólogas/os e, optativamente, nos demais cursos de educação superior. Enfatiza-se que a Política Nacional de Educação Especial na Perspectiva da Educação Inclusiva (MEC, 2008) define a Educação Especial como modalidade transversal a todos os níveis, etapas e modalidades, cuja função é disponibilizar recursos e serviços de acessibilidade bem como o atendimento educacional especializado, complementar à formação das/os estudantes com deficiência, transtornos globais do desenvolvimento e altas habilidades/superdotação. Entre os recursos e serviços de acessibilidade disponibilizados pelas instituições de ensino superior (IES), destacam-se o tradutor e intérprete de Língua Brasileira de Sinais, guia intérprete, equipamentos de tecnologia assistiva e materiais pedagógicos acessíveis, atendendo às necessidades específicas das/os estudantes. Cabe às IES a responsabilidade pelo provimento desses serviços e recursos em todas as atividades acadêmicas e administrativas (MEC, 2013).

Reflexo da expansão da educação superior e das políticas de acesso, evidencia-se o ingresso paulatino de estudantes com deficiência em cursos de graduação, evocando discussões acerca dessa temática. É importante mencionar que, até a década de 1990, os censos educacionais não apontavam o número de alunos com deficiência no ensino superior brasileiro, evidenciando a invisibilidade desses alunos e "impossibilitando, até mesmo, chegar a indicativos mais concretos sobre sua real situação educacional e, por consequência, direcionar de forma mais precisa políticas inclusivas" (MOREIRA et al., 2011, p. 131). No Censo Educacional de 2000, tem-se o número de alunas/os com deficiências - física, auditiva, visual nas IES do país: 2.155. Em 2005, esse número sobe para 6.022 alunas/os, evidenciando um aumento de 179,4\%, entre os anos de 2000 e 2005 (BRASIL, 2006). Em 2006, havia 6.460 alunas/os e em 2007 totalizavam 4.880.381 matrículas de alunas/os no ensino superior, mas apenas $0,13 \%$ apresentavam alguma deficiência (BRASIL, 2009).

Comparativamente, no Censo da Educação Superior de 2019 (INEP,2020) notifica que 48.520 estudantes com deficiência estavam matriculadas/os, sendo que 30.211 (62,26\%) estavam em instituições privadas e 18.306 (37,72\%), em instituições públicas de ensino. Da parcela de estudantes matriculados em instituições públicas, 13.971 (76,06\%) estavam em 
instituições federais, $4.120(22,50 \%)$ em estaduais e 218 (1,19\%) em municipais. Se comparadas à população geral, apenas $0,56 \%$ das matrículas no ensino superior são de estudantes com deficiência, o que indica o contingente ainda pouco expressivo deste grupo no acesso à educação, justificando a importância de investigações que se pautem pela análise deste cenário.

Martins et al. (2015, p.1009) indicam que "é preciso investigar criticamente as causas da presença inexpressiva de estudantes com deficiência no ensino superior quando se comparado aos números de matrículas na educação fundamental”. A potencialidade dessas informações incidiria sobre o acesso, a permanência e a conclusão do ensino superior pelas/os estudantes com deficiência. Nessa direção, a investigação tem como objetivo analisar o percurso universitário de alunas/os com deficiência, a partir da perspectiva de histórias de vida, evocando elementos que possam avaliar dimensões como inclusão, aprendizagem, relação com professoras/es e colegas, potencialidades e dificuldades existentes nesse processo.

\section{Produções acadêmicas relativas aos universitários com deficiência}

As produções acadêmicas atinentes à inclusão de alunas/os com deficiência no ensino superior brasileiro majoritariamente estão relacionadas às universidades públicas (ALMEIDA, FERREIRA, 2018; GARCIA et al., 2018; MARTINS et al (2018); MELO, ARAÚJO, 2018; DUARTE et al, 2015; CIANTELLI, LEITE, 2016; CASTRO, ALMEIDA, 2014; ANACHE, CAVALCANTI, 2013; MOREIRA et al., 2011).

Martins et al. (2018. p. 20-1) realizou mapeamento em três universidades federais, assinalando grande dificuldade de obter os dados em virtude dos procedimentos variados e, muitas vezes, ainda não sistematizados para identificar as/os estudantes com deficiência. Os fatores elencados pelos investigadores para esse contexto são os seguintes: a) a participação de pessoas com deficiência no ensino superior público brasileiro é recente, b) a obrigatoriedade das IES prestarem informações ao INEP sobre as matrículas desse público deu-se a partir de 2014, constituindo-se um procedimento novo; c) a autodeclaração, adotada como procedimento exclusivo para identificação desse público, pode incorrer na fragilidade dos dados, subnotificação ou supernotificação do índice de estudantes com deficiência.

Almeida e Ferreira (2018, p.67) verificaram falhas nos dados oficiais acerca da presença de alunas/os com deficiência na educação superior brasileira, que estão "relacionadas tanto à ausência de mecanismos para levantamento desses dados na instituição base, quanto ao não reconhecimento da condição de deficiência por parte dos alunos que a possuem". Os 
pesquisadores também evidenciaram que a inclusão foi considerada pelos sujeitos da educação superior enquanto "provimento de condições de acessibilidade arquitetônica, indicando um despreparo e um desconhecimento para o provimento de condições de permanência para este aluno, perpetuando barreiras à sua participação em igualdade de condições".

Melo e Araújo (2018) identificaram, entre as dificuldades das/os alunos com deficiência pela instituição de ensino superior pública investigada, situações de vulnerabilidade econômica que impactam no seu desempenho acadêmico e possíveis situações de evasão. Os pesquisadores afirmam, diante desse contexto, que não é suficiente apenas contar com núcleo de apoio, com a adaptação arquitetônica e eliminação de barreiras de comunicação ou atitudinais, mas é necessário adotar ações efetivas para a garantia da permanência dessas/es alunas/os.

Duarte et al. (2013) afirmam que é necessário investir na produção e distribuição de materiais pedagógicos apropriados, na qualificação das/os professoras/es, na infraestrutura adequada para ingresso, acesso e permanência nas diversas instituições de ensino. Moreira et al. (2011), ao indagarem alunas/os com deficiência sobre questões relevantes para sua permanência, identificaram a importância de conhecimentos acerca das/os estudantes pelas/os professores, técnicas/os administrativas/os e colegas da universidade. Em investigação desenvolvida por Garcia et al. (2018), as/os alunos indicaram a falha na disponibilização e adaptação de materiais pedagógicos, sendo definidas ações pela instituição para garantir o desempenho acadêmico dos alunos, como a concessão de bolsas de monitoria, embora haja restrições das/os discentes quanto ao preparo das/os profissionais responsáveis por esse serviço. Anache e Cavalcante (2018) também referem essa sinalização na pesquisa realizada com estudantes de universidade pública, pois as/os alunas/os indicaram dificuldades no processo de aprendizagem, apontando a necessidade de mudanças no projeto político-pedagógico dos cursos para contemplar suas modalidades de aprendizagem, e investimentos para a capacitação de professores do ensino superior.

Silva et al. (2012) investigaram demandas de docentes de universidades privadas para a formação de alunas/os com deficiência, obtendo respostas como capacitação, horários especiais para atender as/os alunas/os e aplicar provas, remuneração para reuniões específicas, redução do número de alunas/os em turmas integradas por estudantes com deficiência, e ainda remuneração extra ou salário diferenciado em função de atividades com essas/es alunas/os. As/os professoras/es indicaram a importância de contarem com avaliação médica a fim de serem informados sobre as limitações da/o aluno e poderem apoiá-la/o - questões que sugerem uma concepção da deficiência relacionada não só à patologia, mas também à defasagem das condições para aprendizagem, tomando-a como característica predominante em detrimento de 
outros aspectos da/o aluna/o a serem considerados. Considerando essas produções acadêmicas e atentando para a importância de estudo que ampliasse o conhecimento no âmbito do ensino superior privado e na perspectiva das/os alunas/os concluintes, foi desenvolvida pesquisa de campo explicitada a seguir.

\section{Método}

A investigação qualitativa, de natureza aplicada e na perspectiva de histórias de vida, teve entrevistas como fonte de coleta de dados. Desse modo, propõe-se a escutar esses sujeitos, a partir de depoimentos que são autobiografias, que, além de testemunho histórico, permitem compreender a evolução da pessoa no tempo, iluminando as possibilidades de acessar a coletividade que ali está implícita (Bosi, 1993). Ao revisitar sua história, a/o participante juntamente com a/o pesquisador/a, busca situar o que contribuiu para que tenha se tornado o que é; compartilha o que sabe sobre si mesmo e sobre o que o rodeia, na tentativa de compreender melhor as relações que a/o forjaram (JOSSO, 2006).

As/os participantes são sujeitos com deficiência, alunas/os universitárias/os de instituição privada de ensino superior, contatadas/os a partir de listagem de matrículas com essa identificação na instituição. Foram inicialmente acessadas/os via e-mail, sendo informadas/os sobre objetivo e característica da pesquisa e convidadas/os a participarem das entrevistas. Os critérios de inclusão foram os seguintes: ter pelo menos uma deficiência, ser formanda/o no ensino superior, ter freqüência nas disciplinas, assinar o termo de consentimento. O projeto de pesquisa obteve registro e aprovação pela plataforma Brasil sob número 51829115.2.0000.5307, observando os procedimentos éticos estabelecidos para a pesquisa científica em Ciências Humanas.

As entrevistas com as/os alunas/os foram gravadas em áudio e contaram com intérprete de Libras, no caso de dois alunos que não fazem leitura labial (G. e M.). Tratando-se da perspectiva de histórias de vida, a condução do contato com as/os participantes norteia-se pelas memórias da trajetória na universidade. Para Bosi (1993), os procedimentos de história de vida e perguntas exploratórias possibilitam ao recordador a liberdade de encadear e compor, à sua vontade, os momentos de seu passado. Dessa forma, as lembranças que os recordadores evocam são o mapa afetivo e intelectual da sua experiência e da experiência de seu grupo. Essa opção metodológica contempla a compreensão individual e coletiva da experiência da deficiência.

A partir da leitura reiterada dos depoimentos das/os participantes, busca-se não somente identificar recorrências e agrupá-las, como também ordenar a narrativa em um eixo diacrônico. 
Essa diacronia é construída para fazer dialogar diferentes contextos espaço-temporais que situam acontecimentos inscritos em um conjunto de depoimentos que conformam um testemunho (SANTOS, 2000). Essa nova configuração dá origem a uma nova organização do material coletado pelas histórias de vida, originando-se as categorias temáticas de análise. Amado e Ferreira (2017, p. 171) consideram que os estudos (auto) biográficos “constituem uma fonte de conhecimento sociocultural dos indivíduos e dos grupos, comunidades e sociedades em que eles se inserem, de relevo para a (re) construção da memória e da identidade individual e coletiva”. Nesse ensejo, descrevem-se os resultados obtidos na investigação realizada a seguir.

\section{Apresentação e análise dos resultados}

Inicialmente são apresentados os sujeitos da pesquisa, identificados no quadro abaixo:

Quadro 1 - Identificação dos sujeitos da pesquisa

\begin{tabular}{l|l|l|l|l}
\hline Entrevistado & Idade & Escola EM & Forma ingresso & Deficiência \\
\hline Amanda & 36 & Escola Privada & Diplomado & Física / Congênita \\
\hline Cassia & 26 & Escola Privada & Vestibular & Auditiva/ Adquirida \\
\hline Carolina & 24 & Escola Pública & PROUNI & Auditiva/ Congênita \\
\hline Cintia & 32 & Escola Pública & PROUNI & Visual/ Adquirida \\
\hline Gabriela & 38 & $\begin{array}{l}\text { Escola Especial } \\
\text { Privada }\end{array}$ & Vestibular & Surda/ Congênita \\
\hline Marcio & 29 & $\begin{array}{l}\text { Escola Especial } \\
\text { Pública }\end{array}$ & Vestibular & Surdo/ Congênita \\
\hline Karina & 32 & Escola Privada & Vestibular & Visual/ Adquirida \\
\hline Ricardo & 38 & Escola Pública & Vestibular & Visual/ Adquirida \\
\hline
\end{tabular}

Os nomes são fictícios

Fonte: Pesquisadores (2017).

A idade média das/os alunas/os participantes é de 31 anos, o que sugere o ingresso no ensino superior não imediato à conclusão do ensino médio e /ou o tempo no ensino médio (e mesmo fundamental ) mais estendido, salientando-se que somente duas alunas cursaram EJA. O tempo médio de permanência na universidade é de 5,8 anos, sendo que o tempo máximo é de 10 anos, evidenciado em aluna que realizou trocas de curso. Em relação à escolarização da/o entrevistada/o surda/o - Gabriela e Marcio - ocorreu em escolas especiais e Carolina, deficiente auditiva, cursou escola pública regular em todo o seu percurso de escolarização. Os três participantes que experienciaram a deficiência quando adolescentes ou adultos - Cintia, Karina e Ricardo - cursaram escolas públicas. Em relação às políticas de acesso ao ensino superior, somente dois alunos são oriundos dessa modalidade (PROUNI), prevalecendo o ingresso via 
vestibular. $\mathrm{O}$ ingresso anterior de outros com deficiência auditiva e a indicação do professor da escola especial foram decisivos para a escolha da universidade por dois entrevistados - Márcio e Gabriela.

Gabriela, Karina e Cintia são as primeiras da família a cursarem o ensino superior. O irmão de Márcio, também surdo, cursa ensino superior na mesma instituição, mas “ [...] os meus pais não têm segundo grau completo - pois eles são surdos também - porque antigamente os surdos não tinham escola, eles paravam na quinta, sexta série, não tinham a tecnologia que a gente tem hoje, então eles não conseguiram estudar muito. ",

Karina e Márcio fizeram trocas de curso em função das dificuldades encontradas no decorrer da escolha inicial, da atividade profissional e das indicações institucionais diante das exigências da formação. Os alunos abdicaram de preferências nas quais encontravam maior identidade - os cursos de Geologia e Ciências Contábeis, respectivamente - como projetos futuros, diante do contexto que vivenciaram na universidade e das exigências da empresa em que Márcio trabalha. Andressa realiza sua segunda diplomação, visto que, após a conclusão, não se identificou com a habilitação de sua formação - licenciatura - reconhecendo que prefere atuar no bacharelado, com atividades de pesquisa. Diante dessa definição, decidiu optar por curso que já estava em suas pretensões há algum tempo, a Psicologia. Todas/os as/os entrevistadas/os, exceto Ricardo, vivenciaram trocas de disciplinas, no decorrer da formação, sendo que quatro deles fizeram essa solicitação, a pedido coordenação do curso, em função de ajustes institucionais para alocação de intérpretes. Estas mudanças - trocas de disciplinas e de cursos - estão presentes na vida acadêmica de muitas/os universitárias/os, mas observa-se que os aspectos que motivaram tais ocorrências para essas/es alunas/os possuem contornos próprios, relacionados à experiência da deficiência, em alguns momentos, e possuem repercussões com diferentes implicações em seu percurso.

\section{O ingresso e a experiência da universidade}

O ingresso na vida universitária foi difícil para Gabriela: "Senti-me mal, muitos ouvintes e só eu surda. Não estava acostumada". Karina explicita: "O meu ingresso foi um pouco complicado. Primeiro eu tive que me aceitar e depois aceitar os outros. " Márcio identifica o processo que estabeleceu: “[...] a questão do atendimento, a troca com os colegas, a questão da gestão que eu fui aprendendo, expandindo meu conhecimento, os apoios". Amanda enfatiza um aspecto que facilitou sua permanência, pois ingressou transferida de outra universidade: “ [...] das pessoas que ficam no portão, até as pessoas que te dão aula, que estão ao teu lado, são muito próximas, é tudo muito receptivo." 

construção a partir do ensino em escolas regulares, instituído pelo Decreto No 6571/2008, mas concretizado a partir das ações e ideias de todos os envolvidos neste momento histórico e social, Ricardo analisa:

\begin{abstract}
A inclusão muitas vezes - se você ler criticamente esse contexto, irá encontrar nas entrelinhas - parece que a inclusão é uma licença para que a pessoa com deficiência seja liberada para a convivência ao nosso mundo, como se fosse uma concessão. Por exemplo: uma coleguinha do meu filho que tem Síndrome de Down... muitas pessoas vão olhar e falar - Que legal, ela está podendo estar ali. Mas quantos irão olhar e falar - Que legal, as outras crianças convivendo com ela.[...] A minha experiência dentro da faculdade, é de que eu só fui entender a questão da inclusão aqui e de que quantos colegas sabem e entendem sobre inclusão porque convivem comigo. Isso não é inclusão? Para mim isso é inclusão!
\end{abstract}

As diferenças do contexto de aprendizado - para as/os alunas/os participantes da investigação que cursaram escolas especiais - foram expressas pelas seguintes manifestações:

[...] porque todos os professores dominavam libras, só me deparei com as dificuldades no nível superior. Tinha os colegas que falavam juntos, perguntavam, os professores respondiam muito rápido, o interprete precisava pedir para o professor falar com mais calma. Os colegas foram aprendendo a falar mais devagar. Os professores também faziam os power points oralisando e não colocavam legenda. Pedi e fizeram as mudanças necessárias para facilitar o meu aprendizado, foi um processo. Gabriela [...] antes os surdos aprendem as palavras (na escola) para depois aprender o conteúdo, e aqui na faculdade não, [...] é direto, porque a gente entra e está ali misturado com os ouvintes [...].é muita informação, porque a gente aprende, mas através da intérprete. é bem diferente do que era a escola, mas eu me esforcei, tive paciência e me senti bem. Márcio

O choque maior foi quando eu entrei na faculdade: vou ter que aprender a me virar, vou ter que aprender a conviver com o pessoal. O ensino técnico também foi assim, $o$ primeiro dia que entrei na sala eram pessoas totalmente diferentes. No ensino fundamental ano a ano, com os mesmos, no ensino, no técnico eram pessoas mais velhas, pessoas mais experientes, pessoas mais novas, vou ter que aprender a conviver, então, foi uma virada de chave e eu me desenvolvi. Cintia

As/os entrevistadas/os avaliaram ter encontrado acessibilidade na infraestrutura da universidade, referindo-se ao piso tátil, elevadores e alguns acessos, mas indicam que o site institucional, as placas de sinalização dos prédios e sala e os materiais de aprendizagem não oportunizam as condições necessárias de acessibilidade, sendo desejável mais adaptação, ocorrendo situações de reivindicação das/os alun/asos junto aos serviços da instituição. Ricardo recorda que enfrentou vários problemas relativos à comunicação, especialmente relativos às mensagens com imagens enviadas por e-mails para notificar de atividades/eventos na instituição, bem como da veiculação de conteúdo no Facebook, um recurso que necessita de descrição das imagens para contemplar os estudantes com deficiência visual. 


\section{Aspectos atinentes à formação universitária}

Em relação aos recursos oferecidos às/aos alunas/os, há intérpretes de libras para as/os surdas/os, e quatro entrevistados recorreram à monitoria para superarem dificuldades em relação às disciplinas cursadas. Ainda duas alunas com deficiência visual ao final do curso - a partir de sua solicitação - passaram a contar com ledores a partir de suas reivindicações à instituição, especialmente para disciplinas que envolveram matemática, nas quais era utilizada constantemente a escrita de cálculos no quadro.

Os alunos com deficiência auditiva explicitam as diferentes experiências em relação à provas e avaliações na universidade. Para Márcio, “as provas são muito pesadas, as palavras do português são difíceis de compreender e entender, [...] eu me esforçava para tentar ler e entender e linkar isso com o que eu tinha estudado, mas eu não consegui entender muitas vezes." Carolina avalia que seu "caso é diferente dos outros colegas no quesito assimilação da matéria. Eu teria que estudar todos os dias, nunca deixar acumular matéria na véspera da prova”. Diante da dificuldade de garantir esta condição, a da exigência de alguns professores e do conteúdo eventualmente difícil, a aluna refere ficar ansiosa em muitos momentos.

Karina considera que, ao realizar o trabalho de conclusão de curso (TCC), enfrentou algumas dificuldades, mas afirma que "Consegui mobilizar um setor inteiro que é o EAD para poderem me ajudar a pesquisar [...] Envolvi todo mundo". Ricardo, que também é DV, conta com materiais digitalizados para leitura - especialmente livros e apresentações em power point - processo realizado pela instituição ou pelos colegas, possuindo também software de voz, e contraste e ampliação para a escrita de textos. Porém considera circunstâncias não acessíveis no contexto em que está inserido:

[...] eu sempre consigo de certa forma compensar as adversidades que poderiam vir surgindo, como uma aula com slides em que o professor não lê os slides ou que tenha um vídeo que não é acessível [...] mas foi algo que por vezes, pontualmente em sala de aula, onde eu já me senti excluído. Senti que estava todo mundo participando e eu estava ali, o professor tinha esquecido que eu estava em sala de aula.

Nessa perspectiva, foram relatadas situações em que a relação com a/o professor/a não favorecem a aprendizagem, seja função dos recursos que são disponibilizados seja das atitudes tomadas diante da/o aluna/o: 
[...] os professores de algumas disciplinas têm pouca experiência com o aluno surdo, têm pouco contato, é difícil essa questão da comunicação, [...] falam muito rápido, então o interprete se atrapalha, ou não consegue explicar. Márcio

Os professores somente oralizavam e se viravam para escrever no quadro, era muito confuso, depois de um tempo me acostumei. Tinha um intérprete, mas como o professor falava muito rápido e voltado para o quadro, o intérprete fazia a interpretação, mas eu estava preocupada em escrever, ou eu olhava para o intérprete ou olhava para o quadro. Eu perdia muito tempo. Aí levantava a mão e pedia para o professor falar mais devagar, mas ele seguia igual. [...] Se o professor falasse voltado para frente facilitaria a compreensão por parte do intérprete. Além de ter muitas conversas paralelas dos colegas, o que também dificultava o entendimento pelo intérprete. Gabriela

[...] alguns professores me receberam bem; outros não, mas foi como eu esperava. Nem sempre as pessoas estão preparadas para aceitar uma pessoa com deficiência, quem sabe eu antes de perder a visão não saberia, não estivesse preparada?! Eu não saberia como trabalhar. Karina

No primeiro dia de aula, quando entrei na sala, das três disciplinas, todos os professores ficaram surpresos com a minha presença, porque ninguém tinha sido avisado que teriam uma aluna com necessidade, embora eu tenha entrado pelo ProUni, aluno bolsista PCD. Ninguém sabia que iria ter uma deficiente visual na sala, então, a aula não estava preparada, os professores não estavam preparados, eles estavam assustados com aquela situação, não sabiam como agir. Cintia

\section{Márcio e Gabriela manifestam questões relativas à comunicação e ao acompanhamento}

na aula; as alunas com DV mencionaram a relação com as/os professora/es, situação relatada por Karina: "Uma professora disse: K., sai da aula que eu não sei dar aula para alunos diferentes. [...] Eu disse: se a senhora não sabe dar aula para alunos diferentes? Vamos lá, vou te ensinar. Botei meu computador em cima da mesa e lá fiquei"' Contudo, recebeu, no dia seguinte, a ligação do coordenador do curso indicando que seria melhor trocar de turma, ao que ela respondeu negativamente; que se manteria. Avalia que não foi uma experiência fácil, mas considera que conseguiu ultrapassar as dificuldades.

Há o reconhecimento de que a interlocução realizada, ao longo da graduação, produziu seus efeitos, modificando, em alguns docentes, a perspectiva de sua qualificação também no processo ensino-aprendizagem:

Eles tinham coração, eles me davam o apoio que eu precisava, eles entendiam o meu jeito, na hora da prova se eu achava difícil. Se a intérprete, por exemplo, não soubesse me dar este auxílio, a gente chamava o professor. e ele vinha e me dava esse apoio. Ele me explicava o que estava sendo dito ali e, com isso, eu conseguia prosseguir fazendo a prova. Márcio

Com o passar dos anos, os professores foram mais tranquilos, os professores foram mais acessíveis, os professores conseguiram se adaptar mais. Agora eu estou com um grande problema com um professor, mas ok, eu sento e converso com ele sem problema nenhum. [...] manda matéria para o meu e-mail, se não dá, manda e-mail para EAD eles vão lá, a gente resolve, resolvemos juntos. Karina 
Fui conversar com a F., que era coordenadora do curso de RH na época, ela me pediu que tivesse um pouco de paciência, pois os professores estavam se deparando com uma nova realidade. Gabriela

Eu sempre pude contar muito com a S., comparecia muito à coordenação, falava para ela (coordenadora) [...] o êxito da minha trajetória no que diz respeito aos fatores externos, passa muito pela pessoa da S. Ricardo

É importante a identificação do apoio enquanto função decisiva na trajetória desses alunos, algumas vezes lembrado na atuação de professoras/es, outras da/o coordenador/a do curso e ainda no setor Núcleo de Apoio ao Estudante (NAE), onde questões relativas à matrícula, intérpretes, disciplinas são tratadas e encaminhadas, como relata Gabriela: “Quando preciso de alguma coisa vou até lá, espero o intérprete e consigo resolver o que preciso, é bem rápido". Para Cintia, "[...] todas as vezes que algo me incomodava na instituição, eu procurava o suporte do NAE, é uma ferramenta que funciona na Instituição e principalmente para o aluno PCD." E ainda: “A” registra que “ [...] foram super acolhedores comigo, nossa, não tenho o que falar [...] uma situação de atendimento no NAE, no Protocolo, foi o acolhimento'. .

No que se refere ao convívio com as/os colegas, as/os alunos surdas/os explicitam contatos restritos, havendo uma interação próxima com a/o intérprete, em detrimento das/dos colegas e professoras/res. O contato por e-mail e whatsapp é o mais efetivo e tende a ocorrer para resolver situação fora e em sala de aula. Gabriela avalia que "A comunicação $e$ relacionamento eram ótimos com os colegas. Parafazer os trabalhos o celular, whatsapp ajuda muito, conversamos, vejo minha parte, depois o intérprete me ajuda no que preciso. Márcio situa como percebe o contexto em que está inserido: "[...] o grupo todo era ouvinte, eu era o único surdo, era difícil. Eles ficavam conversando [...] tinha intérprete sim, mas mesmo assim ficava difícil, porque às vezes os ouvintes falavam todos ao mesmo tempo". Carolina avalia que há pouca interação com as/os colegas e atribui à jornada profissional destes, a restrita disponibilidade para estudar ou trabalhar em grupo, condição diferente da sua, que é dedicada à universidade.

Analisando as potencialidades de aproximação na sala de aula, Cintia entende que, para o estudante com deficiência visual, "não é que a pessoa com deficiência ele seja, antissocial, mas o primeiro passo, infelizmente tem que ser dado pelo vidente". Justifica sua afirmativa pelo fato de que, ao não enxergar, quando se coloca diante de uma conversa já existente entre colegas, pode ser vista como invasiva. A formanda alude a aspectos também presentes no cotidiano da sala de aula que podem ser mediados pela/o professor/a 
Depende muito da pessoa, porque todas as pessoas trazem uma bagagem. Há alguns alunos que estudaram comigo há várias cadeiras atrás que eu nunca falei. Agora que estão estudando com uma professora que sempre me deu suporte, que deve ter tido feito um trabalho, esses alunos hoje me dão suporte. Hoje, por exemplo, eu peguei meu celular chamei uma colega no watts que nunca falo com ela. Ela sempre sentou longe, e eu não enxergo, eu não tenho como pegar e puxar um assunto com ela, uma coisa invisível.

O ideário social da ajuda ou da assistência à pessoa com deficiência, também presente na sala de aula, é analisado por Ricardo, apontando a possibilidade de outras perspectivas neste âmbito:

\begin{abstract}
Neste universo da pessoa com deficiência, uma das grandes falhas é: pessoas que não têm deficiência - mesmo sem se darem conta, se colocam no lugar deste suposto saber: eu sei fazer, eu sei o que é bom pra ti. Ás vezes as pessoas me dizem: Ah, as pessoas não fazem por mal! Mas pra mim isso não é o critério, enquanto eu for avaliar isso, avaliar de que não fizeram por mal, vão sempre fazer. Obviamente a gente tem educação, a gente vai conversar com essas pessoas, mesmo não tendo sido por má intenção, mas partindo do princípio de que não foi, nunca foi, precisa disso, precisa ir ali conversar com o aluno que é surdo, que tem deficiência visual, perguntar o que é melhor pra ti? Esse é o caminho, eu acho, pra qualquer pessoa.
\end{abstract}

\title{
Considerações finais
}

A investigação, que analisou aspectos do percurso universitário de alunas/os com deficiência, a partir da perspectiva de histórias de vida, foi realizada mediante entrevistas com oito alunas/os formandas/os. Considerando o processo recente de inclusão dessas/es alunas/os no ensino superior e a predominância de estudos no âmbito das instituições públicas, a intenção foi produzir elementos para análise dessa experiência no contexto das IES privadas.

Os resultados apontaram que o ingresso na universidade implicou superações advindas do estranhamento relativo ao contexto acadêmico, do desconhecimento das/os professoras/es e colegas, diante de suas necessidades de aprendizagem, e das condições de acessibilidade vivenciadas. As/os alunas/os salientam a importância da interface institucional - serviços, coordenação de curso e colaboradores - para seu acolhimento e resolução de demandas identificadas. Evidencia-se a construção de condições pedagógicas e relacionais para as/os universitários com deficiência, etapa que sucede as questões arquitetônicas que foram iniciais nesse processo inclusivo, havendo novos desafios a serem enfrentados por toda a comunidade acadêmica.

\section{Referências}

ALMEIDA, José Guilherme de Andrade; FERREIRA, Eliana Lucia. Sentidos da inclusão de alunos com deficiência na educação superior: olhares a partir da Universidade Federal de Juiz de Fora. Psicol. Esc. Educ., Maringá, v. 22, n. spe, p. 67-75, 2018. Disponível em: 
http://www.scielo.br/scielo.php?script=sci_arttext\&pid=S1413-

$85572018000400067 \& \operatorname{lng}=$ pt\&nrm=iso. Acesso em: 12 nov. 2017.

AMADO, João; FERREIRA, Sonia. Estudos (auto) biográficos - histórias de vida. In: AMADO, João (coord). Manual de investigação qualitativa em Educação. $3^{\mathrm{a}}$ Ed. Coimbra: Imprensa da Universidade de Coimbra, 2017.

ANACHE, Alexandra Ayach; CAVALCANTE, Lysa Duarte. Análise das condições de permanência do estudante com deficiência na Educação Superior. Psicol. Esc.

Educ., Maringá, v. 22, n. spe, p. 115-125, 2018. Disponível em:

http://www.scielo.br/scielo.php?script=sci_arttext\&pid=S1413-

85572018000400115\&lng=pt\&nrm=iso\&tlng=pt. Acesso em: 12 mar. 2018.

BOSI, Ecléa. A pesquisa em memória social. Psicol. USP, São Paulo, v. 4, n. 1-

2, 1993. Disponível em: https://www.revistas.usp.br/psicousp/article/view/34480/37218. Acesso em: 19 jun. 2017.

BRASIL. Decreto $N^{o} 6.571$ de 17 de setembro de 2008. Dispõe sobre o atendimento educacional especializado. Disponível em: http://www.planalto.gov.br/ccivil_03/_ato20072010/2008/decreto/d6571.htm. Acesso em: 14 fev. 2018.

BRASIL. Censo da Educação Especial de 2000 e 2005: evolução da educação especial no Brasil. Dados Estatísticos por estado das matrículas na educação especial. Brasília: INEP, 2006. Disponível em: http://portal.mec.gov.br/seesp/arquivos/pdf/brasil.pdf. Acesso em: 22 fev. 2018.

BRASIL. Resumo Técnico: Censo da Educação Superior 2007. Brasília: MEC/INEP, 2009. Disponível em:

http://download.inep.gov.br/download/superior/censo/2007/Resumo_tecnico_2007.pdf.

Acesso em: 04 jul. 2017.

CASTRO, Sabrina Fernandes de; ALMEIDA, Maria Amelia. Ingresso e permanência de alunos com deficiência em universidades públicas brasileiras. Rev. bras. educ. espec., Marília, v. 20, n. 2, p. 179-194, jun. 2014. Disponível em: http://www.scielo.br/scielo.php?script=sci_arttext\&pid=S1413-

65382014000200003\&lng=en\&nrm=iso\&tlng=pt. Acesso em: 24 jan. 2018.

CIANTELli, Ana Paula Camilo; LEITE, Lúcia Pereira. Ações Exercidas pelos Núcleos de Acessibilidade nas Universidades Federais Brasileiras. Rev. bras. educ. espec., Marília, v. 22, n. 3, p. 413-428, set. 2016. Disponível em:

http://www.scielo.br/scielo.php?script=sci_arttext\&pid=S1413-

65382013000200011\&lng=pt\&nrm=iso. Acesso em: 02 dez. 2017.

DUARTE, Emerson Rodrigues et al . Estudo de caso sobre a inclusão de alunos com deficiência no Ensino Superior. Rev. bras. educ. espec., Marília, v. 19, n. 2, p. 289300, jun. 2013. Disponível em:

http://www.scielo.br/scielo.php?script=sci_arttext\&pid=S1413-

65382013000200011\&lng=en\&nrm=iso\&tlng=pt. Acesso: em 11 jun. 2017. 
GARCIA, Raquel Araújo Bonfim; BACARIN, Ana Paula Siltrão; LEONARDO, Nilza Sanches Tessaro. Acessibilidade e permanência na educação superior: percepção de estudantes com deficiência. Psicol. Esc. Educ., Maringá, v. 22, n. spe, p. 33-40, 2018 . Disponível em: http://www.scielo.br/scielo.php?script=sci_arttext\&pid=S141365382014000200003\&lng=pt\&nrm=iso. Acesso em: 06 abr. 2017.

\section{INSTITUTO NACIONAL DE ESTUDOS E PESQUISAS EDUCACIONAIS ANÍSIO} TEIXEIRA (INEP). Sinopse Estatística da Educação Superior 2016. Brasília: Inep, 2017. Disponível em: http://portal.inep.gov.br/basica-censo-escolar-sinopse-sinopse. Acesso em: 05 mar. 2018.

\section{INSTITUTO NACIONAL DE ESTUDOS E PESQUISAS EDUCACIONAIS ANÍSIO} TEIXEIRA (INEP). Sinopse Estatística da Educação Superior 2019. Brasília: Inep, 2020. Disponível em: < http://portal.inep.gov.br/basica-censo-escolar-sinopse-sinopse >. Acesso em 25 nov. de 2020.

JOSSO, Marie Christine. As figuras de ligação nos relatos de formação: ligações formadoras, deformadoras e transformadoras. Educ. Pesqui., São Paulo, v. 32, n. 2, p. 373-383, ago. 2006 . Disponível em: http://www.scielo.br/scielo.php?script=sci_arttext\&pid=S151797022006000200012\&lng=en\&nrm=iso\&tlng=pt. Acesso em: 04 set. 2017. http://dx.doi.org/10.1590/S1517-97022006000200012.

MARTINS, Diléia Aparecida; LEITE, Lúcia Pereira; LACERDA, Cristina Broglia Feitosa de. Políticas públicas para acesso de pessoas com deficiência ao ensino superior brasileiro: uma análise de indicadores educacionais. Ensaio: aval.pol.públ.Educ., Rio de Janeiro, v. 23, n. 89, p. 984-1014, dez. 2015. Disponível em: http://www.scielo.br/scielo.php?script=sci_arttext\&pid=S0104$40362015000400984 \& \operatorname{lng}=$ t\&nrm=iso. Acesso em: 14 fev. 2018.

MELO, Francisco Ricardo Lins Vieira de; ARAUJO, Eliana Rodrigues. Núcleos de Acessibilidade nas Universidades: reflexões a partir de uma experiência institucional. Psicol. Esc. Educ., Maringá, v. 22, n. spe, p. 57-66, 2018. Disponível em: http://www.scielo.br/pdf/pee/v22nspe/2175-3539-pee-22-spe-57.pdf. Acesso em: 26 jan. 2018.

MOREIRA, Laura Ceretta; BOLSANELLO, Maria Augusta; SEGER, Rosangela Gehrke. Ingresso e permanência na Universidade: alunos com deficiências em foco. Educ. rev., Curitiba, n. 41, p. 125-143, set. 2011. Disponível em: http://www.scielo.br/scielo.php?script=sci_arttext\&pid=S0104$40602011000300009 \& \operatorname{lng}=e n \& n r m=i s o \& t l n g=p t$. Acesso em: 16 mar. 2018.

SANTOS, Antônio César de Almeida. Fontes orais: testemunhos, trajetórias de vida e história. Revista Via Atlântica, 4, 1-10, 2000. Disponível em: http://www.uel.br/cch/cdph/arqtxt/Testemuhostrajetoriasdevidaehistoria.pdf. Acesso em: 11 abr. 2018.

SILVA, Ani Martins; CYMROT, Raquel; D'ANTINO, Maria Eloisa Famá. Demandas de docentes do ensino superior para a formação de alunos com deficiência. Rev. Bras. Estud. Pedagog., Brasília, v. 93, n. 235, p. 667-697, dez. 2012 . Disponível em: http://www.scielo.br/scielo.php?script=sci_arttext\&pid=S2176$66812012000400008 \& \operatorname{lng}=$ pt\&tlng=pt. Acesso em: 26 set. 2017. 